\title{
Thermal Degradation of Statistical Copolymers of 2-Vinyl Pyridine with Functional Methacrylates
}

\author{
Stavros Zouganelis, Ioanna Kanisoglou, Christina Kabaki, Marinos Pitsikalis \\ Industrial Chemistry Laboratory, Department of Chemistry, National and Kapodistrian University of \\ Athens, Panepistimiopolis Zografou, Athens Greece
}

\begin{abstract}
Conventional free radical polymerization was employed for the synthesis of statistical copolymers of 2-vinyl pyridine (2VP) with either 2-butoxyethyl methacrylate (BuOEMA), di(ethylene glycol) methyl ether methacrylate (DEGMA) or oligo(ethylene glycol) methyl ether methacrylate bearing a side chain with an average number of 5 ethylene glycol units (OEGMA300). Copolymers having different compositions in the two monomers were obtained. The thermal decomposition of these statistical copolymers was studied by Thermogravimetric Analysis (TGA) and Differential Thermogravimetry (DTG). The Ozawa-Flynn-Wall (OFW) and Kissinger methodologies were adopted for the calculation of the activation energies of the thermal decomposition. The results of these studies were compared with those measured for the corresponding P2VP, PBUOEMA, PDEGMA and POEGMA300 homopolymers so as to correlate the structures of the copolymers with their properties.
\end{abstract}

Keywords: statistical copolymers, 2-vinyl pyridine, functional methacrylates, thermogravimetric analysis, differential thermogravimetry, thermal decomposition

\begin{abstract}
Abbreviations:
TGA- Thermogravimetric Analysis, DTG- Differential Thermogravimetry, 2VP- 2-vinyl pyridine, BuOEMA 2-butoxyethyl methacrylate, DEGMA -di(ethylene glycol)methyl ether methacrylate, OEGMA300-oligo(ethylene glycol) methyl ether methacrylate, OFW - Ozawa-Flynn-Wall method, SEC-Size Exclusion Chromatography, NMR- Nuclear Magnetic Resonance
\end{abstract}

\section{INTRODUCTION}

Copolymerization is a very important tool in polymer science because it provides scientists the possibility to manipulate the physical and chemical properties of a polymer chain, e.g. solubility [1], crystallinity [2] and glass transition temperature (Tg) [3] in order to create new materials of scientific interest as well as diverse applications, such as drug transfer systems [4], photoresists for lithography [5] and smart materials [6]. Its utility is stressed by the large number of commercial applications and investigations that have been conducted to correlate the structure with the properties of the materials [3], [7].

Copolymerization has been studied extensively, both experimentally and theoretically [8]. The main body of work is focused on the elucidation of the copolymer composition, the determination of the monomer reactivity ratios, the monomer sequence distribution and the kinetics of the copolymerization [9].

Free radical copolymerization is the most important copolymerization technique, since it is experimentally less demanding compared to other copolymerization methodologies and it can be applied to a wide range of monomers. The free radical copolymerization of 2-vinyl pyridine (2VP) with either 2-butoxyethyl methacrylate (BuOEMA), di(ethylene glycol) methyl ether methacrylate (DEGMA), or oligo(ethylene glycol) methyl ether methacrylate with number average molecular weight $300 \mathrm{~g} / \mathrm{mol}\left(\mathrm{OEGMA}_{300}\right)$ was the focus of previous studies. The monomer structures are given in Scheme 1. It was found that the reactivity ratios of $2 \mathrm{VP}, \mathrm{r}_{2 \mathrm{VP}}$ were higher in all statistical copolymers $\left(\mathrm{r}_{2 \mathrm{VP}}=3.04\right.$ and $\mathrm{r}_{\text {BuOEMA }}=0.48$ for the P2VP-co-PBuOEMA copolymers [10], $\mathrm{r}_{2 \mathrm{VP}}=1.57$ and $r_{\text {DEGMA }}=0.92$ for the P2VP-co-PDEGMA copolymers [10], whereas $r_{2 \mathrm{VP}}=1.08$ and $\mathrm{r}_{\text {OEGMA300 }}=0.23$ for the P2VP-co-POEGMA300 copolymers [11]) indicating a kinetic preference for the incorporation of the $2 \mathrm{VP}$ units in the copolymer structure. These findings prompted the present study of the kinetics of 
the thermal decomposition of these statistical copolymers by Thermogravimetric Analysis (TGA) and Differential Thermogravimetry (DTG). These results were correlated with those obtained from the corresponding homopolymers P2VP, PBuOEMA, PDEGMA and POEGMA ${ }_{300}$ to study the effect of the copolymer structure and composition on the thermal properties of the copolymers.<smiles>C=Cc1ccccn1</smiles>

2-Vinyl Pyridine<smiles>C=C(C)C(=O)OCCOC</smiles>

Di(ethylene glycol) methyl ether methacrylate<smiles>C=C(C)C(=O)OCCOCC</smiles>

Butoxyethyl methacrylate<smiles>C=C(C)C(=O)OCCOC</smiles>

Oligo(ethylene glycol) methyl ether methacrylate (DPave=5)

Scheme1. Structure of the Monomers

\section{EXPERIMENTAL SECTION}

\subsection{Materials}

The synthesis of the statistical copolymers has been described in detail elsewhere [10], [11]. Briefly, all manipulations were performed using high vacuum techniques. The monomers were vacuum distilled from calcium hydride just prior to use in order to remove inhibitors and humidity. The copolymerization reactions were performed in glass reactors in bulk. 2,2' Azobisisobutyronitrile (AIBN) in the concentration of $0.1 \%$ wt was the initiator. The mixture of the two monomers and the initiator was degassed using three freeze-thaw cycles, and the reactors were flame-sealed. The copolymerizations were conducted at $50-60^{\circ} \mathrm{C}$ for $2-3$ hours. The polymers were precipitated in $\mathrm{n}$ heptane, redissolved in chloroform and reprecipitated once more. The same procedure was repeated as many times as necessary in order to remove all remaining quantities of the unreacted monomers. Finally, the polymers were dried overnight in a vacuum oven.

\subsection{Thermogravimetric Analysis}

The thermal stability of the homopolymers and the copolymers was studied by thermogravimetric analysis (TGA) and Differential Thermogravimetry (DTG) with a Q50 TGA model from TA instruments. The samples were placed in platinum crucibles and an empty platinum crucible was used as reference. The samples were heated from ambient temperatures up to $600^{\circ} \mathrm{C}$ in a $60 \mathrm{~mL} / \mathrm{min}$ flow of $\mathrm{N}_{2}$ at heating rates of $3,5,7,10,15$ and $20^{\circ} \mathrm{C} / \mathrm{min}$.

\section{RESUlTS AND DISCUSSION}

\subsection{Free Radical Homopolymerization and Copolymerization Reactions}

The free radical copolymerizations of VP, BuOEMA, DEGMA and OEGMA 300 were conducted in bulk using AIBN as the initiator. The conversions in all cases were lower than $10 \%$ in order to satisfy the differential copolymerization equation. The molecular characteristics of both the homopolymers and the copolymers are shown in Table 1. The molecular weights were measured by Size Exclusion Chromatography, SEC using a calibration curve constructed by polystyrene standards. The compositions of the copolymers in the various monomers were measured by NMR or UV analysis at $252 \mathrm{~nm}$, where only the 2VP monomer units absorb. The copolymers are symbolized by the various 
Thermal Degradation of Statistical Copolymers of 2-Vinyl Pyridine with Functional Methacrylates

feed molar ratios of the monomers prior the copolymerization, e.g. 2VP-BuOEMA 20-80 is used for the copolymer P2VP-co-PBuOEMA, synthesized from a molar feed composition 20\% 2VP and 80\% BuOEMA.

Table1. Macromolecular characteristics of the homopolymers and the statistical copolymers

\begin{tabular}{|c|c|c|c|}
\hline Sample & ${ }^{a} M_{n} \times 10^{-3}$ & ${ }^{\mathrm{a}} \mathbf{I}=\mathbf{M}_{\mathrm{w}} / \mathbf{M}_{\mathbf{n}}$ & ${ }^{5} 2 \mathrm{VP}$ moles \% \\
\hline P2VP & 214.0 & 1.46 & 100 \\
\hline PBuOEMA & 81.5 & 1.23 & 0 \\
\hline PDEGMA & 280.0 & 1.41 & 0 \\
\hline POEGMA $_{300}$ & 288.5 & 1.28 & 0 \\
\hline 2VP-BuOEMA 20/80 & 83.5 & 1.36 & 45.6 \\
\hline 2VP-BuOEMA 40/60 & 77.2 & 1.39 & 61.2 \\
\hline 2VP-BuOEMA 50/50 & 65.8 & 1.73 & 72.7 \\
\hline 2VP-BuOEMA 60/40 & 65.3 & 1.34 & 82.0 \\
\hline 2VP-BuOEMA 80/20 & 78.4 & 1.37 & 92.1 \\
\hline $2^{2 \mathrm{VP}-O E G M A_{300}} 20 / 80$ & 465.0 & 1.42 & 35.8 \\
\hline $2^{2 \mathrm{VP}-O E G M A_{300}} 50 / 50$ & 363.1 & 3.50 & 66.2 \\
\hline $2_{\mathrm{VP}-O E G M A_{300} 60 / 40}$ & 472.6 & 1.40 & 70.3 \\
\hline 2 VP-OEGMA ${ }_{300} 80 / 20$ & 430.1 & 1.80 & 82.6 \\
\hline 2VP-DEGMA 20/80 & 1078 & 1.34 & 33.9 \\
\hline 2VP-DEGMA 40/60 & 1358 & 1.43 & 61.0 \\
\hline 2VP-DEGMA 50/50 & 1182 & 1.41 & 72.3 \\
\hline 2VP-DEGMA 60/40 & 1091 & 1.39 & 78.1 \\
\hline 2VP-DEGMA 80/20 & 695.0 & 1.36 & 91.0 \\
\hline
\end{tabular}

a. by SEC in $\mathrm{CHCl}_{3}$ at $40^{\circ} \mathrm{C}$, b. by ${ }^{1} \mathrm{H}-\mathrm{NMR}$ in $\mathrm{CDCl}_{3}$ at $25^{\circ} \mathrm{C}$ or by UV analysis at $252 \mathrm{~nm}$.

\subsection{Thermal Decomposition of the Homopolymers and the Statistical Copolymers}

The homopolymers and the statistical copolymers were thermally degraded at different heating rates under inert atmosphere. The temperatures where the thermal decomposition is initiated and completed along with the temperatures at the maximum rate of thermal decomposition are provided in Tables 2 (homopolymers) and 3 (statistical copolymers) and characteristic thermograms from DTG are given in Figures 1-7. Additional plots are given in the supporting information section.

Table2. TGA results for the homopolymers at the heating rate $10^{\circ} \mathrm{C} / \mathrm{min}$

\begin{tabular}{|c|c|c|c|c|}
\hline Sample & Start $\left({ }^{\mathbf{0}} \mathbf{C}\right)$ & Finish $\left({ }^{\mathbf{0}} \mathbf{C}\right)$ & Peak 1 $\left({ }^{\mathbf{0}} \mathbf{C}\right)$ & Peak 2 $\left({ }^{\mathbf{0}} \mathbf{C}\right)$ \\
\hline P2VP & 363.91 & 457.16 & 414.40 & -- \\
\hline PBuOEMA & 210.18 & 408.49 & 305.70 & 317.98 \\
\hline PDEGMA & 180.62 & 396.66 & 262.85 & 327.07 \\
\hline POEGMA 300 & 237.93 & 390.75 & 331.62 & 338.44 \\
\hline
\end{tabular}

Table3. TGA results for the copolymer samples at the heating rate $10^{\circ} \mathrm{C} / \mathrm{min}$

\begin{tabular}{|c|c|c|c|}
\hline Sample & Start $\left({ }^{\circ} \mathrm{C}\right)$ & Finish $\left({ }^{\circ} \mathrm{C}\right)$ & Peak $\left({ }^{\circ} \mathrm{C}\right)$ \\
\hline P2VP-PBuOEMA 20-80 & 272.04 & 425.32 & 365.75 \\
\hline P2VP-PBuOEMA 40-60 & 270.22 & 424.86 & 373.92 \\
\hline P2VP-PBuOEMA 50-50 & 300.24 & 440.33 & 377.56 \\
\hline P2VP-PBuOEMA 60-40 & 291.60 & 437.14 & 378.01 \\
\hline P2VP-PBuOEMA 80-20 & 304.79 & 433.96 & 388.93 \\
\hline P2VP-POEGMA $_{300} 20-80$ & 282.50 & 425.32 & 366.64 \\
\hline P2VP-POEGMA $_{300} 50-50$ & 279.77 & 441.24 & 369.37 \\
\hline P2VP-POEGMA $_{300} 60-40$ & 299.33 & 442.13 & 378.47 \\
\hline P2VP-POEGMA $_{300} 80-20$ & 270.22 & 448.06 & 393.48 \\
\hline P2VP-PDEGMA 20-80 & 258.50 & 392.09 & 322.99 \\
\hline P2VP-PDEGMA 40-60 & 271.74 & 404.18 & 356.39 \\
\hline P2VP-PDEGMA 50-50 & 278.08 & 403.61 & 355.81 \\
\hline P2VP-PDEGMA 60-40 & 267.13 & 413.40 & 360.42 \\
\hline P2VP-PDEGMA 80-20 & 290.74 & 415.70 & 368.48 \\
\hline
\end{tabular}




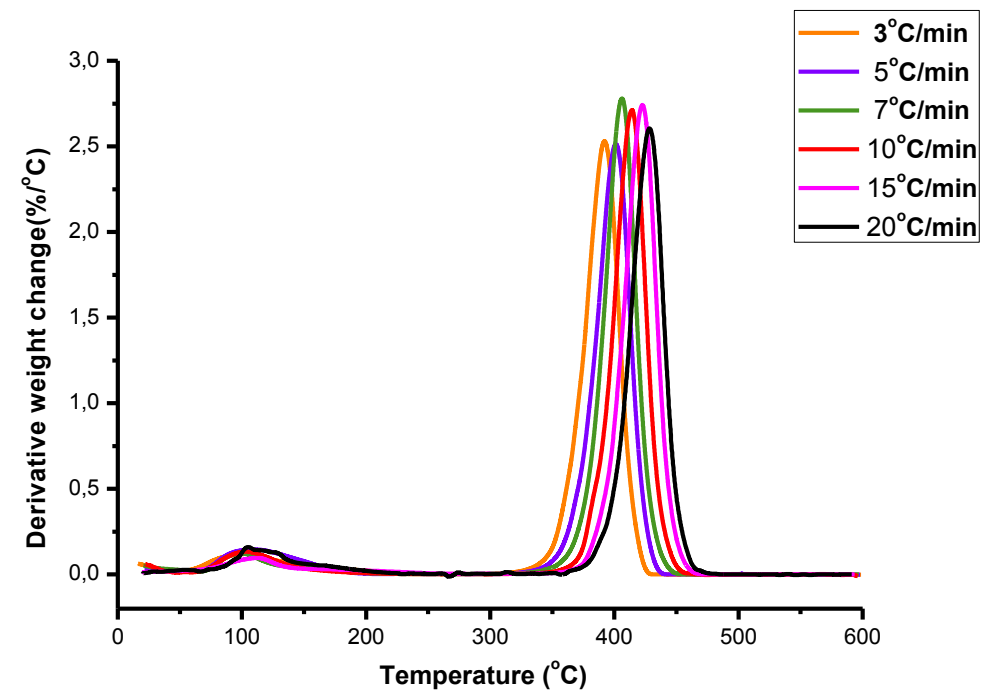

Figure1. Derivative Weight Loss with Temperature for P2VP under Different Heating Rates

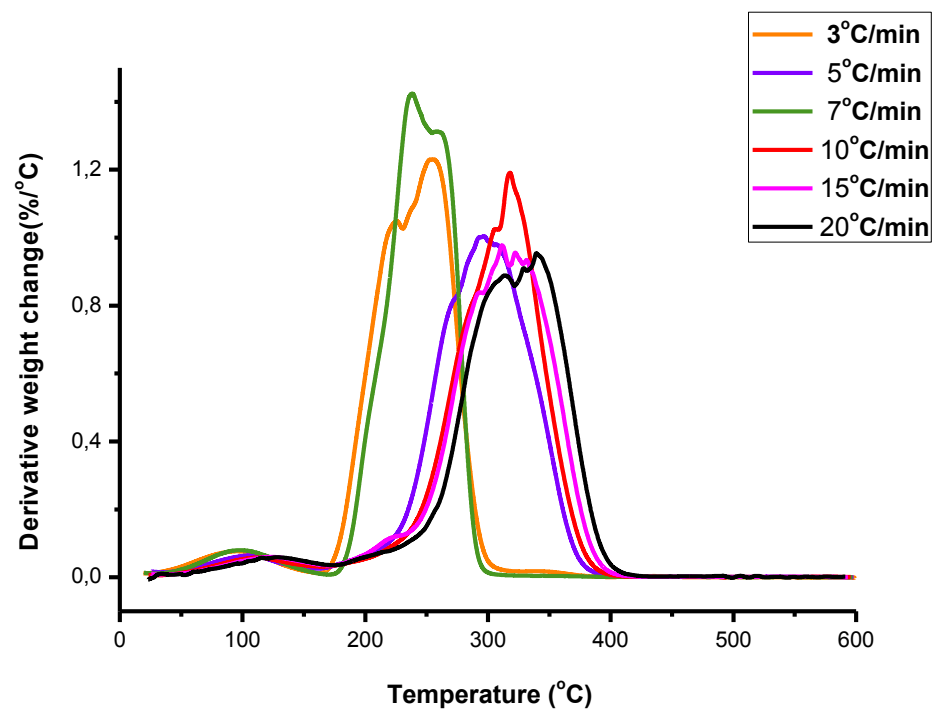

Figure2. Derivative Weight Loss with Temperature for PBuOEMA under Different Heating Rates

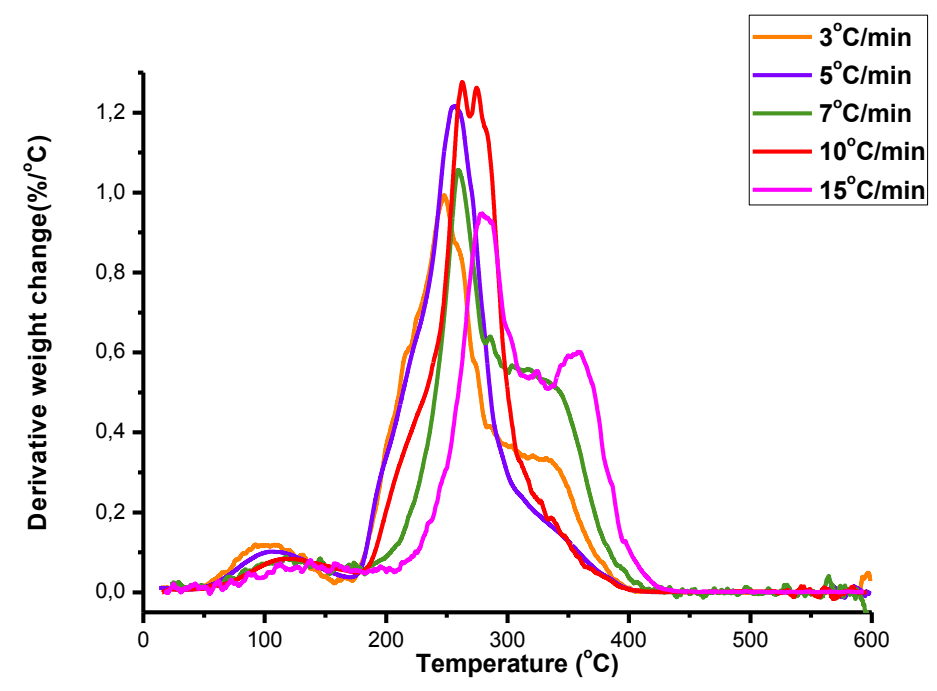

Figure3. Derivative Weight Loss with Temperature for PDEGMA under Different Heating Rates 


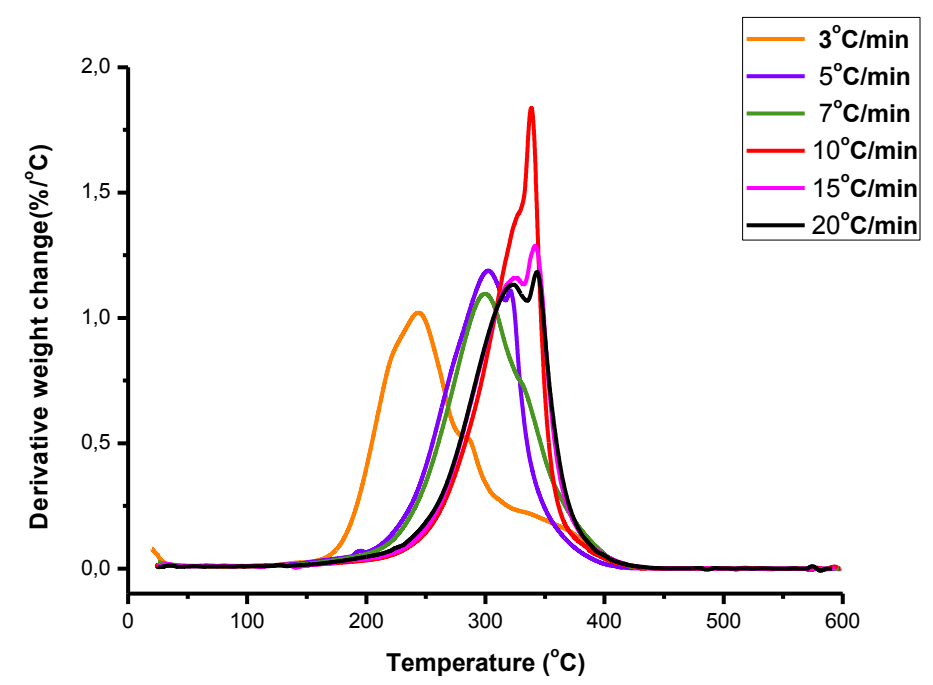

Figure4. Derivative Weight Loss with Temperature for POEGMA300 under Different Heating Rates

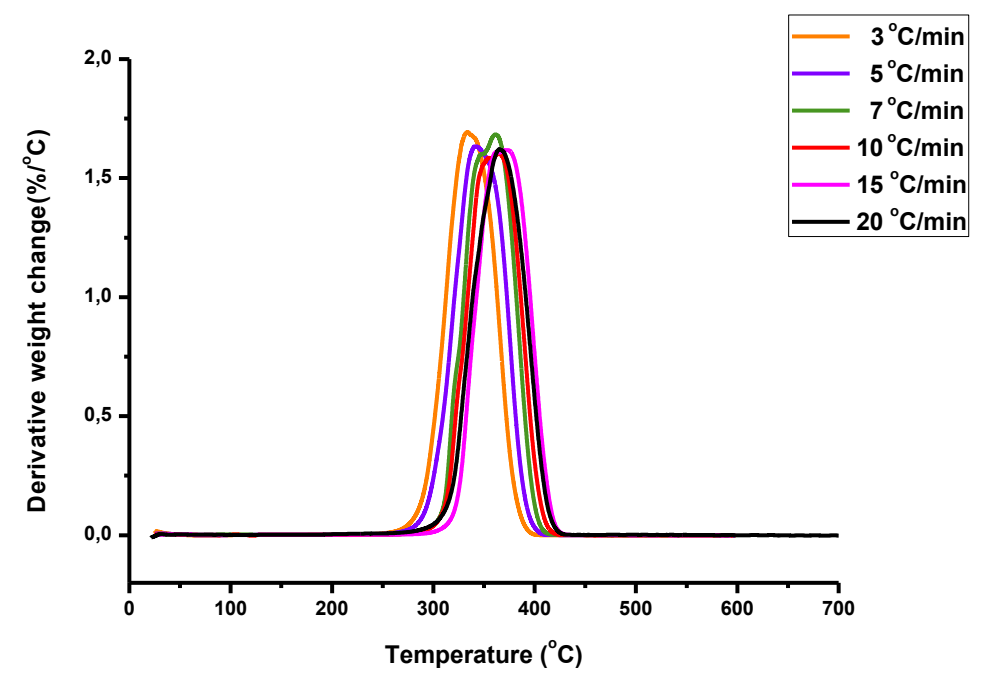

Figure5. Derivative Weight Loss with Temperature for P2VP-PBuOEMA 20-80 under Different Heating Rates

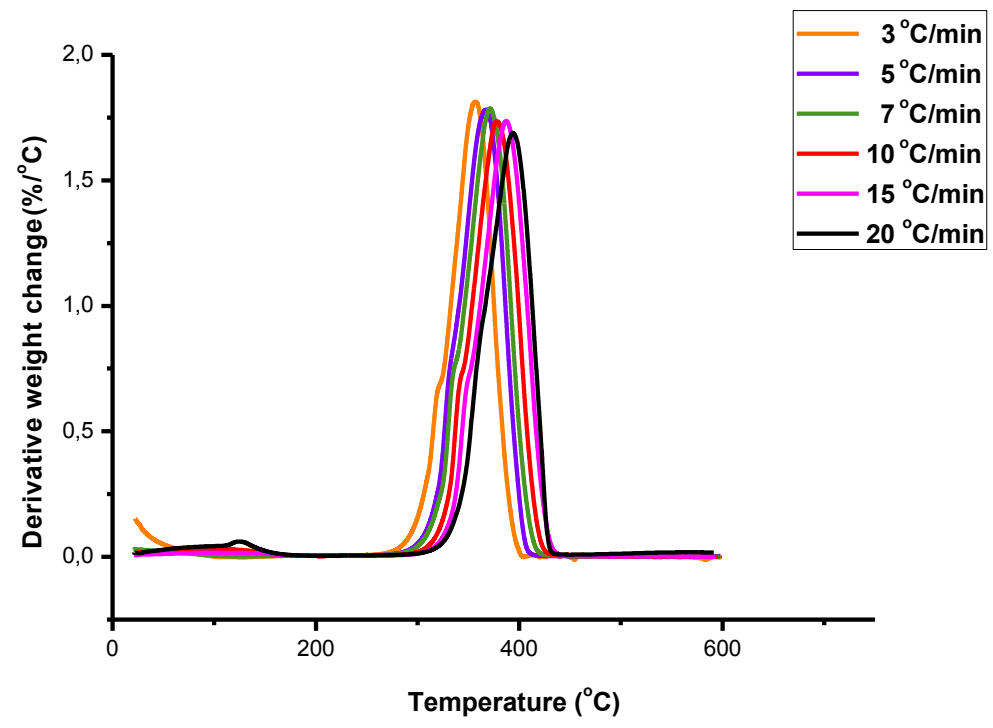

Figure6. Derivative Weight Loss with Temperature for P2VP-POEGMA300 60-40 under Different Heating Rates 


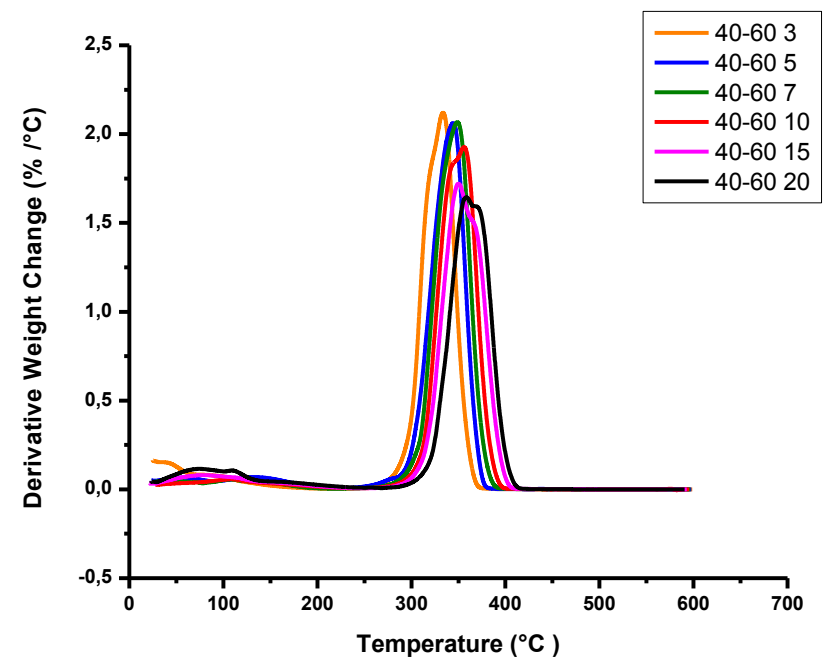

Figure7. Derivative Weight Loss with Temperature for P2VP-PDEGMA 40-60 under Different Heating Rates

DTG revealed that single decomposition peaks appear for P2VP at different heating rates. For PBuOEMA, however, DTG indicated the presence of a single decomposition peak at lower heating rates, while at higher heating rates a more complex pattern consisting of two peaks appeared. A similar decomposition behavior was also observed for PDEGMA and POEGMA 300 homopolymers, obviously due to the similar chemical structure of these polymers, since all three are polymethacrylates bearing ethylene glycol side groups. These results indicate that for the specific polymethacrylates the decomposition pattern is complex and involves the simultaneous decomposition of the polymer backbone and the side chains.

The thermal decomposition of P2VP is initiated and completed at higher temperatures compared to the three polymethacrylates. In addition, the decomposition peaks in DTG graphs occur at higher temperatures for $\mathrm{P} 2 \mathrm{VP}$ as well. These data unambiguously indicate that $\mathrm{P} 2 \mathrm{VP}$ is thermally more stable than the corresponding polymethacrylates, obviously due to the presence of the aromatic pyridine ring. The range of decomposition temperatures is narrower for P2VP than that of PBuOEMA, PDEGMA and POEGMA ${ }_{300}$ supporting the conclusion that a simpler thermal decomposition mechanism exists for P2VP. Comparing the temperatures of decomposition at the maximum rate of decomposition, $\mathrm{Tp}$, the following order is noted: $T \mathrm{p}_{\mathrm{P} 2 \mathrm{VP}}>\mathrm{T} \mathrm{p}_{\text {OEGMA300 }}>\mathrm{Tp}_{\mathrm{PDEGMA}}>$ Tp $p_{\text {PBuoEma }}$ and seems to be the order of thermal stability of the homopolymers. Among the polymethacrylates it is evident that upon increasing the size of the side groups (number of ethylene oxide units) the thermal stability increases. The higher thermal stability of PDEGMA compared to PBuOEMA leads to the conclusion that the introduction of a higher number of oxygen atoms at the side chain leads to increased thermal stability. These conclusions can be further supported considering the thermal stability of poly(ethylene oxide).

In the case of the statistical copolymers P2VP-co-PBuOEMA DTG revealed that only a single decomposition peak is observed, similar to the behavior of the P2VP homopolymer. Thus, the thermal decomposition behavior of P2VP prevails in the copolymer. This observation can be attributed to the much higher reactivity ratio of $2 \mathrm{VP}$ over that of BuOEMA, which leads to copolymers with much higher contents in 2VP units. Upon increasing the 2VP content, the temperatures where thermal decomposition is initiated and completed, as well as that of the decomposition peak in DTG all increase. These temperatures are within those found for the respective homopolymers but are closer to those of the P2VP homopolymer, further demonstrating the effect of $2 \mathrm{VP}$ monomer units on the overall behavior of the copolymer.

Similar behavior was observed for the P2VP-co-PDEGMA and P2VP-co-POEGMA300 copolymers. The thermal degradation behavior of the copolymers is dominated by the 2VP content. In addition to the previous comments it should be noted that the range of the temperatures of decomposition is much narrower for the copolymers compared to the respective polymethacrylates. Comparing the temperatures of decomposition at the maximum rate of decomposition, $\mathrm{Tp}$, it can be concluded that they follow the order: $\mathrm{Tp}_{\mathrm{P} 2 \mathrm{VP}-\mathrm{co} \text {-PBuOEMA }}>\mathrm{T}_{\mathrm{P} 2 \mathrm{VP}-\mathrm{co-OEGMA} 300}>\mathrm{T} \mathrm{p}_{\mathrm{P} 2 \mathrm{VP}-\mathrm{co-DEGMA}}$. This should also be the order of thermal stability of the copolymers. It is rather surprising that the copolymers with the 
BuOEMA are thermally more stable since the corresponding homopolymer presents the lowest thermal stability of all the homopolymers. This discrepancy can be explained by the fact that the P2VP-co-PBuOEMA copolymers have higher 2VP contents compared to the other copolymers.

\subsection{Kinetics of the Thermal Decomposition of the Homopolymers and the Statistical Copolymers}

The kinetics of the thermal decomposition of the statistical copolymers was studied by TGA measurements. The activation energy, Ea, of mass loss upon heating was calculated using both the isoconversional Ozawa-Flynn-Wall (OFW) [12] and Kissinger [13] methods. The OFW approach is a "model free" method which assumes that the conversion function $\mathrm{F}(\alpha)$, where $\alpha$ is the conversion, does not change upon altering of the heating rate, $\beta$, for all values of $\alpha$. The OFW method involves the measurement of the temperatures corresponding to fixed values of $\alpha$ from experiments at different heating rates $\beta$. Therefore, plotting $\ln \beta$ vs $1 / T$ in the form:

$$
\ln \beta=\ln \frac{\mathrm{AE}}{\mathrm{R}}-\ln F(\alpha)-\frac{\mathrm{E}}{\mathrm{RT}}
$$

This should result in straight lines with slopes directly proportional to the activation energy where $\mathrm{T}$ is the absolution temperature. A is the pre-exponential factor $\left(\mathrm{min}^{-1}\right)$ and $\mathrm{R}$ is the gas constant $(8,314$ $\mathrm{J} / \mathrm{K}$.mol). If the determined activation energy is the same for the various values of $\alpha$, then a single-step degradation reaction can be concluded. The OFW method is the most useful method for the kinetic interpretation of thermogravimetric data, obtained from complex processes like the thermal degradation of polymers. This method can be applied without knowing the reaction order.

The activation energy Ea was also calculated from plots of the logarithm of the heating rate vs. the inverse of temperature at the maximum reaction rate in constant heating experiments, according to the Kissinger method. The equation for the Kissinger method is the following:

$$
\ln \left(\frac{\beta}{T_{p}^{2}}\right)=\ln \frac{A R}{E}+\ln \left[n\left(1-a_{p}\right)^{n-1}\right]-\frac{E}{R T_{p}}
$$

where $T_{p}$ and $a_{p}$ are the absolute temperature and the conversion at the maximum weight loss and $\mathrm{n}$ is the reaction order. The Ea values can be calculated from the slope of the plots of $\ln \left(\beta / T_{p}{ }^{2}\right) v s .1 / T_{p}$.

The activation energy values, Ea, of the homopolymers resulting from the OFW method are displayed in Table 4, whereas characteristic plots are given in Figures 8-11. It is obvious that the Ea values depend on the degree of thermal decomposition, especially for sample POEGMA300. This is a manifestation of the rather complex mechanism of thermal degradation of these polymers. The Ea values of samples vary with the following order: $\mathrm{Ea}_{\mathrm{P} 2 \mathrm{VP}}>\mathrm{Ea}_{\text {OEGMA } 300}>\mathrm{Ea}_{\text {PDEGMA }}>\mathrm{Ea}_{\mathrm{PBuOEMA}}$, in agreement with the thermal stability of the homopolymers, as previously discussed. Similar conclusions were drawn by the Kissinger method. Characteristic plots are given in Figures 12-15, and the Ea values are displayed in Table 5.

Table4. Activation Energies for the Homopolymers from the OFW Method

\begin{tabular}{|l|l|l|l|l|}
\hline $\begin{array}{l}\text { Weight } \\
\text { Loss }(\%)\end{array}$ & P2VP & PBuOEMA & PDEGMA & POEGMA300 \\
\hline 10 & -- & 53.10 & 64.75 & 73.50 \\
\hline 20 & 167.49 & 54.92 & 61.82 & 78.34 \\
\hline 30 & 181.44 & 54.75 & 74.48 & 81.73 \\
\hline 40 & 189.20 & 50.56 & 80.90 & 86.69 \\
\hline 50 & 193.99 & 46.71 & 75.95 & 93.41 \\
\hline 60 & 197.77 & 45.12 & 64.96 & 102.63 \\
\hline 70 & 201.19 & 44.87 & 65.42 & 142.75 \\
\hline 80 & 204.46 & 44.92 & 62.40 & 140.46 \\
\hline 90 & 208.12 & 46.76 & 81.83 & -- \\
\hline
\end{tabular}

Table5. Activation Energies for the Polymers from the Kissinger Method

\begin{tabular}{|c|c|c|}
\hline Sample & $\mathbf{E}_{\mathbf{a} 1}(\mathbf{J})$ & $\mathbf{E}_{\mathbf{a} 2}(\mathbf{J})$ \\
\hline PBuOEMA & 86.88 & 115.18 \\
\hline P2VP-PBuOEMA 20/80 & 118.2 & \\
\hline P2VP-PBuOEMA 40/60 & 161.3 & \\
\hline P2VP-PBuOEMA 50/50 & 198.0 & \\
\hline
\end{tabular}


Stavros Zouganelis et al.

\begin{tabular}{|c|c|c|}
\hline \hline P2VP-PBuOEMA 60/40 & 177.7 & \\
\hline P2VP-PBuOEMA 80/20 & 181.3 & \\
\hline P2VP & 188.3 & \\
\hline P2VP-POEGMA300 20/80 & 203.0 & \\
\hline P2VP-POEGMA300 50/50 & 122.7 & 154.01 \\
\hline P2VP-POEGMA300 60/40 & 168.1 & \\
\hline P2VP-POEGMA300 80/20 & 115.3 & \\
\hline POEGMA300 & 38.99 & \\
\hline P2VP-PDEGMA 20-80 & 111.72 & \\
\hline P2VP-PDEGMA 40-60 & 215.16 & \\
\hline P2VP-PDEGMA 50-50 & 151.23 & 61.62 \\
\hline P2VP-PDEGMA 60-40 & 159.17 & \\
\hline P2VP-PDEGMA 80-20 & 24.67 & \\
\hline PDEGMA & & \\
\hline
\end{tabular}

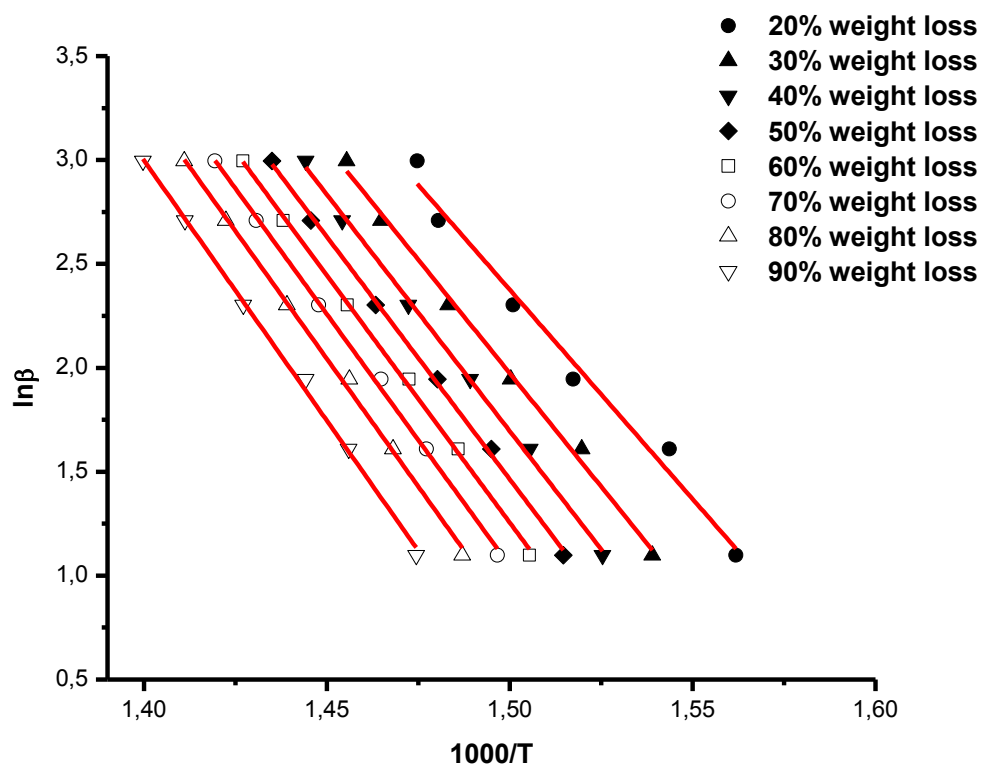

Figure8. $O F W$ plots for $P 2 V P$

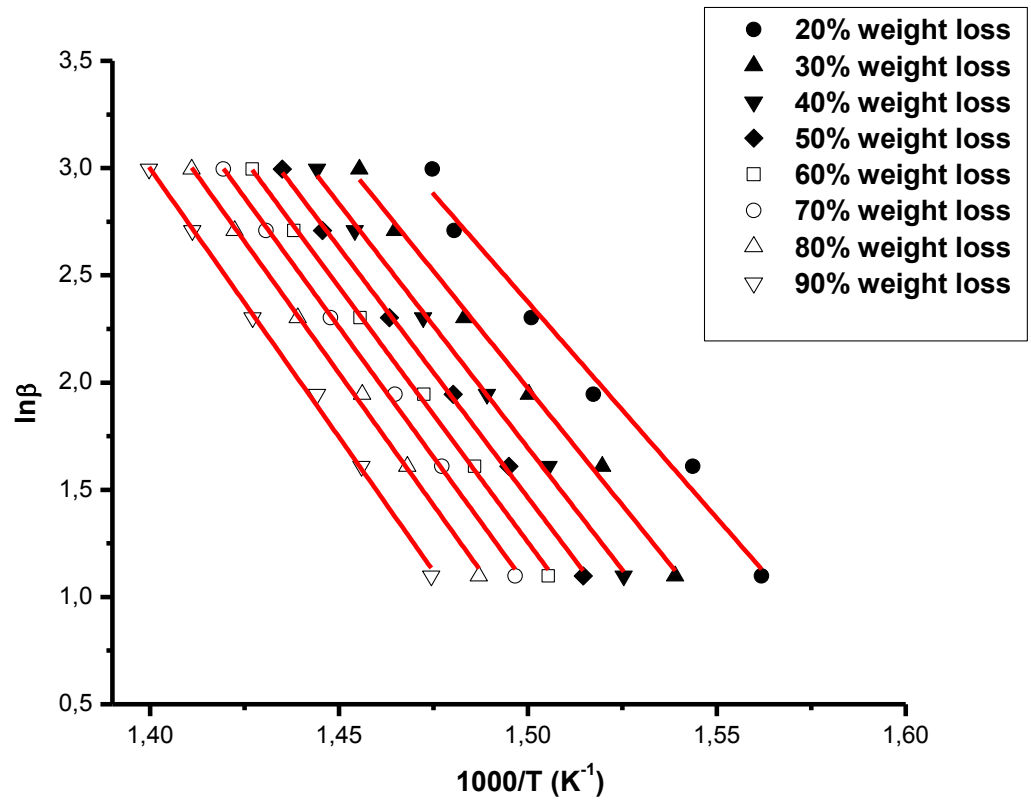

Figure9. OFW plots for $P B \cup O E M A$ 


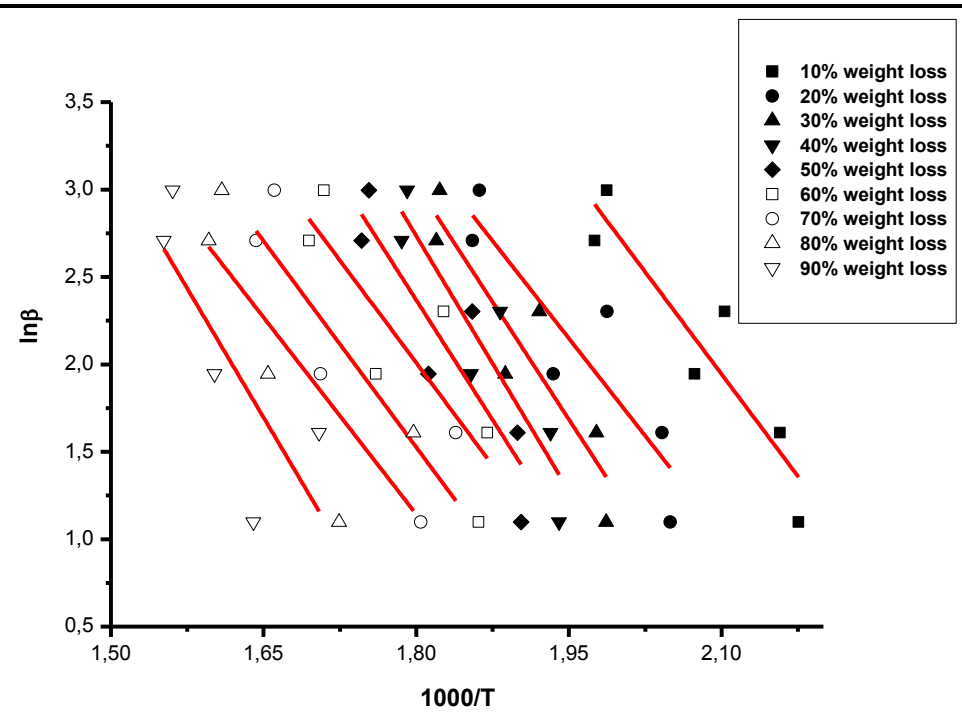

Figure10. OFW plots for PDEGMA

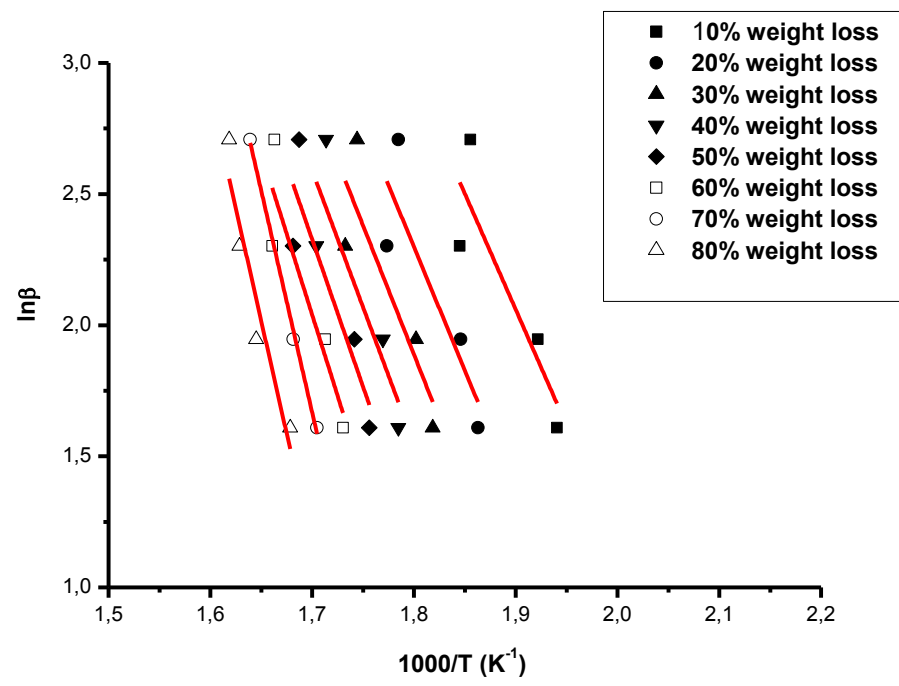

Figure11. OFW plots for POEGMA 300

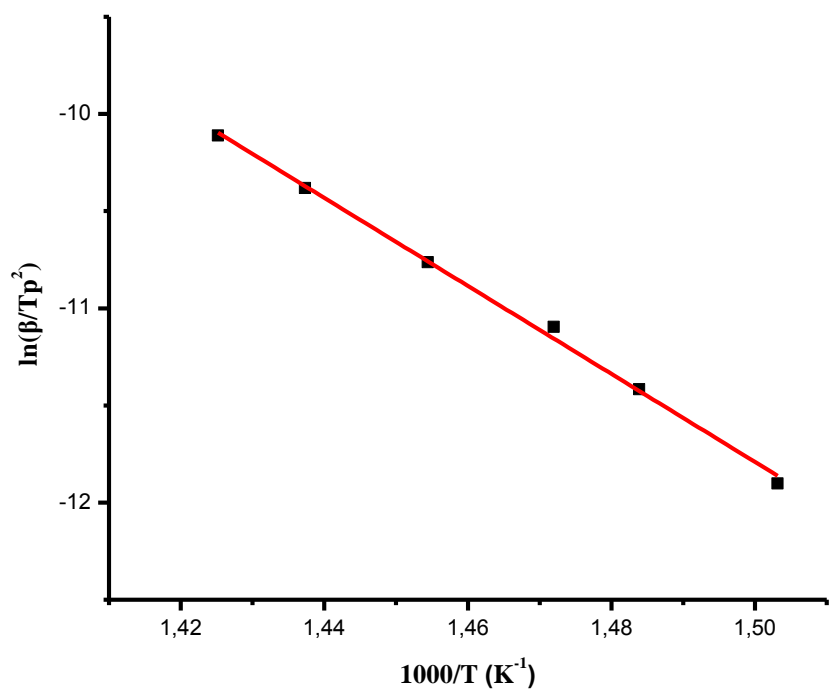

Figure12. Kissinger plot for P2VP 

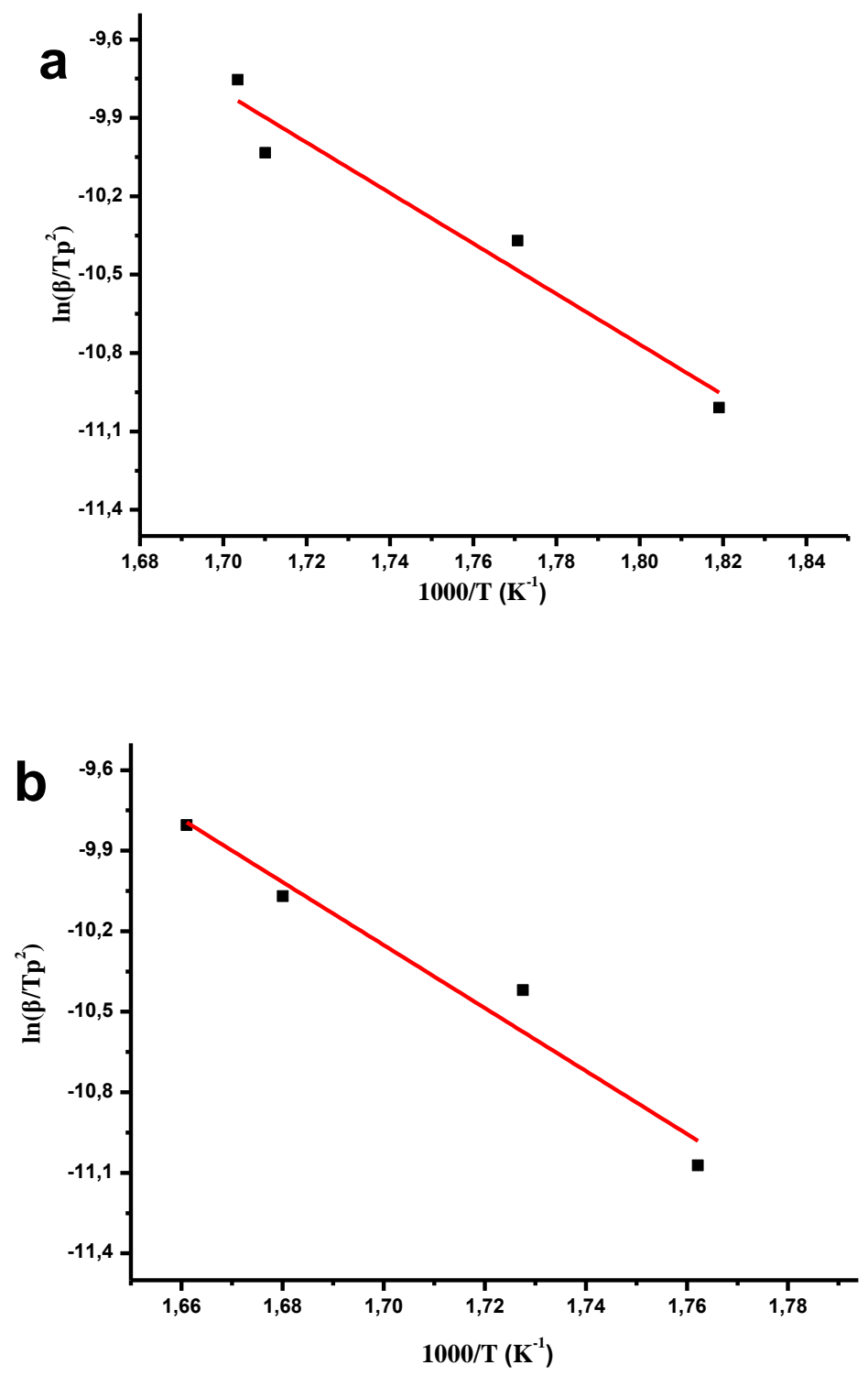

Figure13. (a) Kissinger plot for PBuOEMA first peak (b) Kissinger plot for PBuOEMA second peak

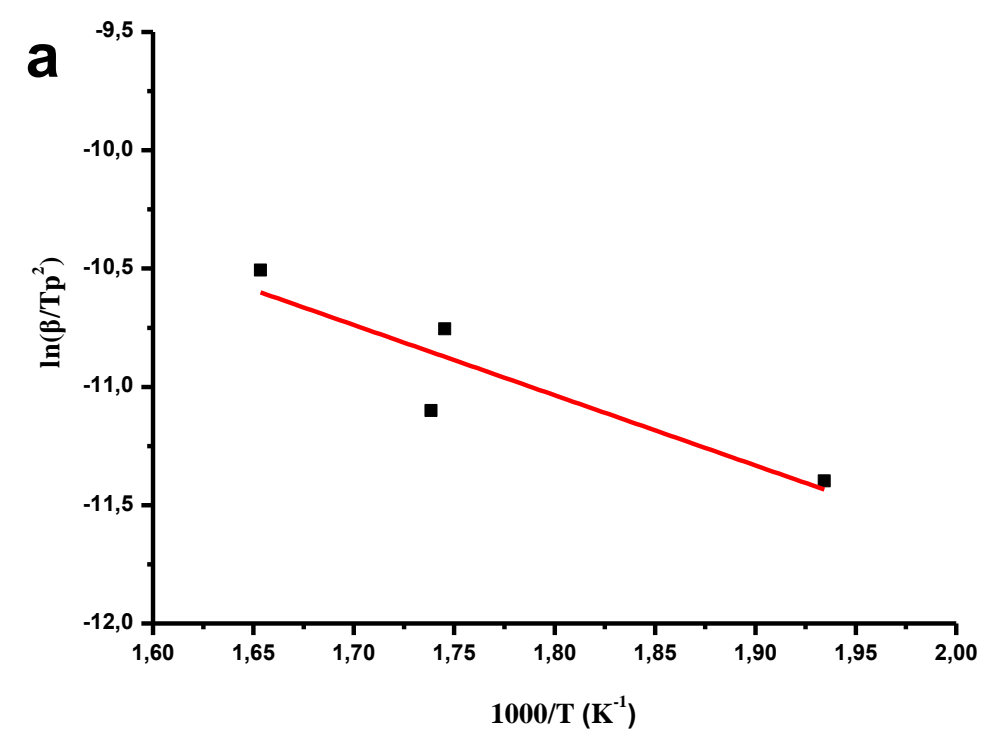




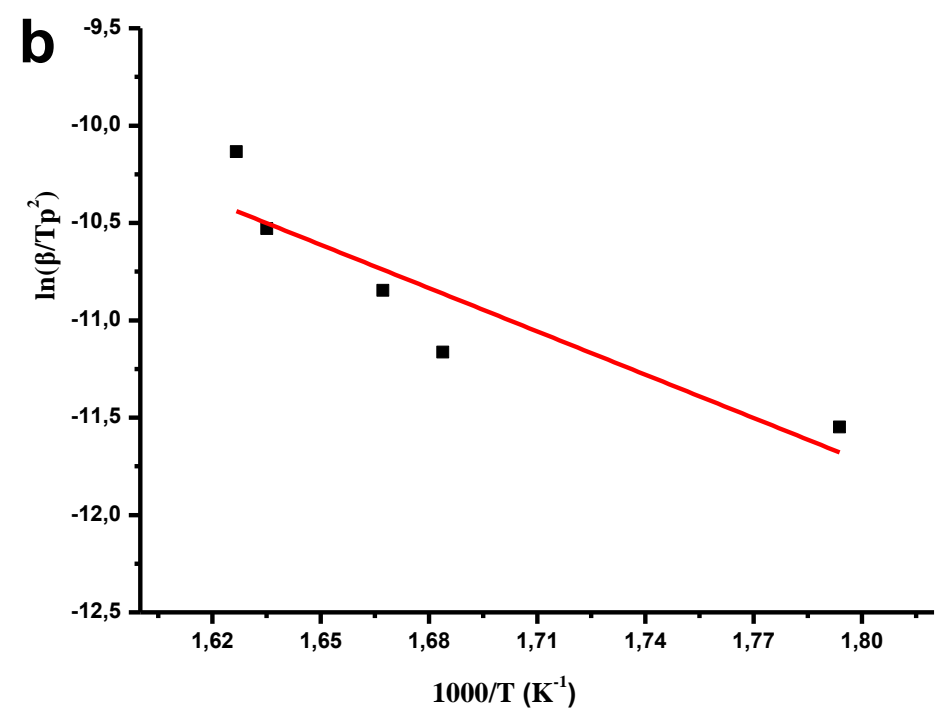

Figure14. (a) Kissinger plot for PDEGMA first peak (b) Kissinger plot for PDEGMA second peak
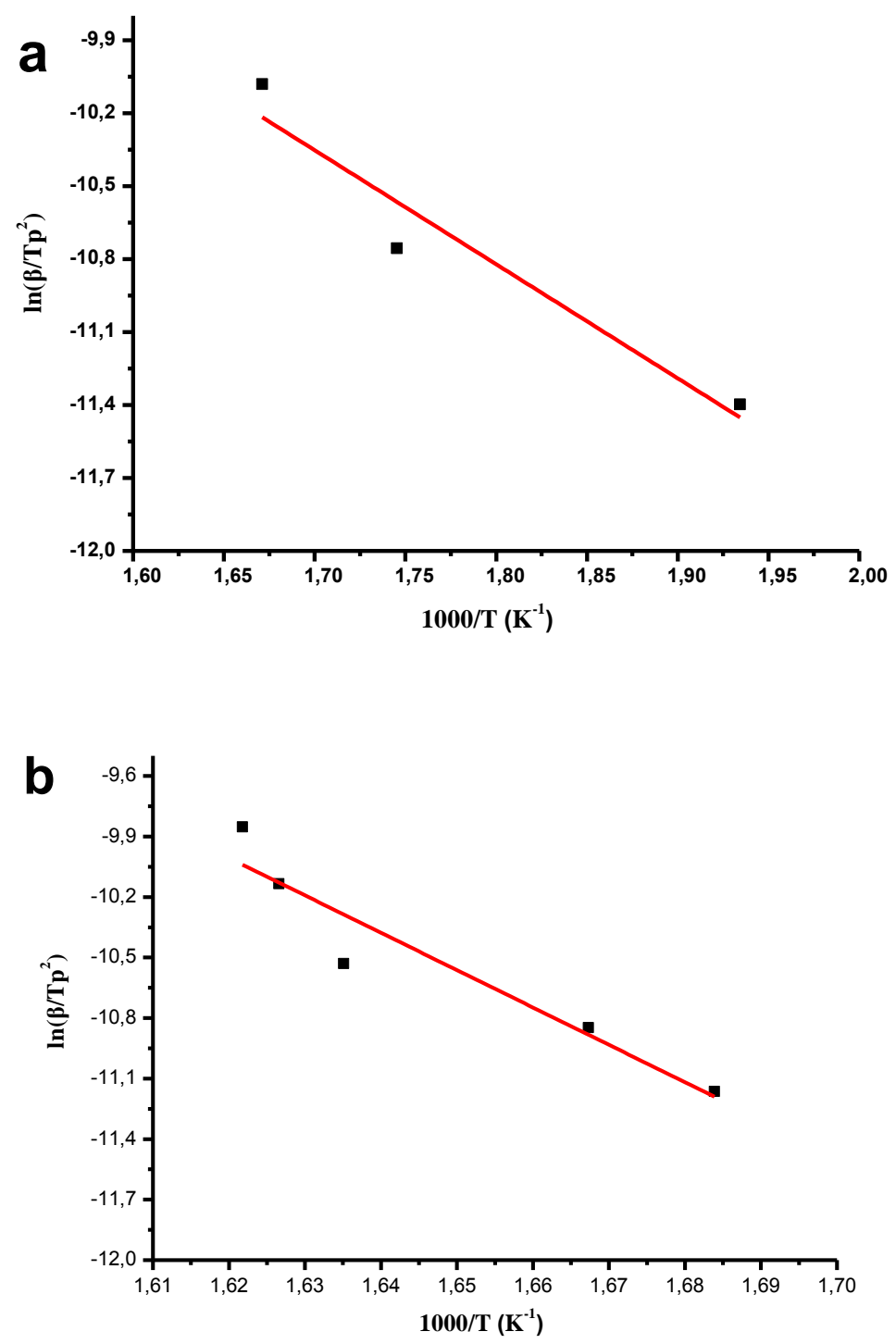

Figure15. (a) Kissinger plot for POEGMA300 first peak (b) Kissinger plot for POEGMA300 second peak 
Stavros Zouganelis et al.

The activation energies Ea of the various copolymers at different weight loses are shown in Tables 68 and characteristic OFW plots are provided in Figures 16-18. These values generally increase upon increasing the degree of decomposition. However, this change is not so pronounced as in the case of the polymethacrylate homopolymers, since the presence of the 2VP monomer units dominates and affects the thermal decomposition behavior of the copolymers. The obtained values are located between those measured for the respective homopolymers, but are always closer to the Ea values of $\mathrm{P} 2 \mathrm{VP}$, due to the higher 2VP content in all copolymers. Comparison of the Ea values of the various copolymers leads to the general conclusion that they follow the order: $\mathrm{Ea}_{\mathrm{P} 2 \mathrm{VP}-\mathrm{co-PBuOEMA}}>\mathrm{Ea}_{\mathrm{P} 2 \mathrm{VP}-\mathrm{co}-}$

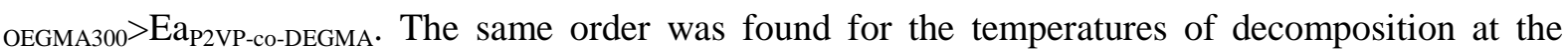
maximum rate of decomposition of the copolymers, confirming their thermal stability. The Ea values were also calculated by the Kissinger method and results are given in Table 5 and characteristic plots in Figures 19-21. It is obvious that the Kissinger equation leads to lower activation energies. However, the same trend regarding the variation of the Ea values with the structures was observed with the OFW approach.

Table6. Activation Energies for the P2VP-PBuOEMA Copolymers from the OFW Method

\begin{tabular}{|c|c|c|c|c|c|}
\hline $\begin{array}{c}\text { Weight } \\
\text { Loss } \\
(\boldsymbol{\%})\end{array}$ & $\begin{array}{c}\text { P2VP- } \\
\text { PBuOEMA } \\
\mathbf{2 0 - 8 0}\end{array}$ & $\begin{array}{c}\text { P2VP- } \\
\text { PBuOEMA } \\
\mathbf{4 0 - 6 0}\end{array}$ & $\begin{array}{c}\text { P2VP-PBuOEMA } \\
\mathbf{5 0 - 5 0}\end{array}$ & $\begin{array}{c}\text { P2VP- } \\
\text { PBuOEMA } \\
\mathbf{6 0 - 4 0}\end{array}$ & $\begin{array}{c}\text { P2VP- } \\
\text { PBuOEMA } \\
\mathbf{8 0 - 2 0}\end{array}$ \\
\hline 10 & 142.86 & 182.58 & 182.08 & 189.54 & 173.67 \\
\hline 20 & 152.79 & 186.81 & 192.11 & 184.50 & 180.70 \\
\hline 30 & 157.64 & 187.86 & 196.73 & 191.84 & 183.92 \\
\hline 40 & 160.96 & 186.20 & 200.12 & 192.23 & 185.80 \\
\hline 50 & 161.82 & 185.56 & 201.95 & 193.86 & 187.88 \\
\hline 60 & 163.79 & 185.21 & 201.68 & 194.90 & 189.48 \\
\hline 70 & 167.54 & 185.45 & 202.32 & 197.46 & 191.89 \\
\hline 80 & 172.61 & 186.52 & 202.30 & 200.17 & 190.60 \\
\hline 90 & 178.24 & 188.70 & 206.16 & 204.07 & 197.76 \\
\hline
\end{tabular}

Table7. Activation energies for the P2VP-PDEGMA copolymers from the OFW method

\begin{tabular}{|l|l|l|l|l|l|}
\hline $\begin{array}{l}\text { Weigh } \\
\text { toss } \\
(\%)\end{array}$ & $\begin{array}{l}\text { P2VP- } \\
\text { PDEGMA 20-80 }\end{array}$ & $\begin{array}{l}\text { P2VP- } \\
\text { PDEGMA 40-60 }\end{array}$ & $\begin{array}{l}\text { P2VP- } \\
\text { PDEGMA 50-50 }\end{array}$ & $\begin{array}{l}\text { P2VP- } \\
\text { PDEGMA60-40 }\end{array}$ & $\begin{array}{l}\text { P2VP- } \\
\text { PDEGMA 80-20 }\end{array}$ \\
\hline 10 & 12.06 & 2.03 & 2.67 & 10.64 & 61.38 \\
\hline 20 & 112.39 & 200.68 & 171.12 & 170.25 & 153.30 \\
\hline 30 & 191.97 & 199.13 & 169.72 & 171.98 & 165.35 \\
\hline 40 & 172.84 & 196.28 & 168.84 & 173.17 & 171.45 \\
\hline 50 & 160.67 & 195.26 & 167.49 & 172.40 & 170.04 \\
\hline 60 & 149.45 & 191.64 & 166.36 & 171.47 & 168.77 \\
\hline 70 & 142.30 & 184.48 & 166.75 & 170.61 & 167.98 \\
\hline 80 & 141.50 & 179.17 & 167.50 & 169.95 & 166.62 \\
\hline 90 & 153.41 & 176.39 & 170.31 & 169.46 & 166.63 \\
\hline
\end{tabular}

Table8. Activation Energies for the P2VP-POEGMA300 Copolymers from the OFW Method

\begin{tabular}{|l|l|l|l|l|}
\hline $\begin{array}{l}\text { Weight Loss } \\
(\boldsymbol{\%})\end{array}$ & $\begin{array}{l}\text { P2VP-POEGMA } \\
\mathbf{2 0 - 8 0}\end{array}$ & $\begin{array}{l}\text { P2VP-POEGMA }_{\mathbf{3 0 0}} \\
\mathbf{5 0 - 5 0}\end{array}$ & $\begin{array}{l}\text { P2VP-POEGMA }_{\mathbf{3 0 0}} \\
\mathbf{6 0 - 4 0}\end{array}$ & $\begin{array}{l}\text { P2VP-POEGMA }_{\mathbf{3 0 0}} \\
\mathbf{8 0 - 2 0}\end{array}$ \\
\hline 10 & 19.85 & 138.06 & 176.04 & 50.33 \\
\hline 20 & -- & 145.12 & 181.25 & -- \\
\hline 30 & -- & 158.11 & 183.45 & 143.76 \\
\hline 40 & 136.61 & 166.10 & 184.10 & 159.60 \\
\hline 50 & 165.50 & 171.70 & 185.75 & 173.54 \\
\hline 60 & 196.51 & 176.21 & 166.35 & 172.07 \\
\hline 70 & 199.41 & 196.53 & 183.12 & 179.42 \\
\hline 80 & 196.08 & 202.45 & 187.83 & 176.20 \\
\hline 90 & 195.51 & 182.85 & 196.54 & 183.36 \\
\hline
\end{tabular}




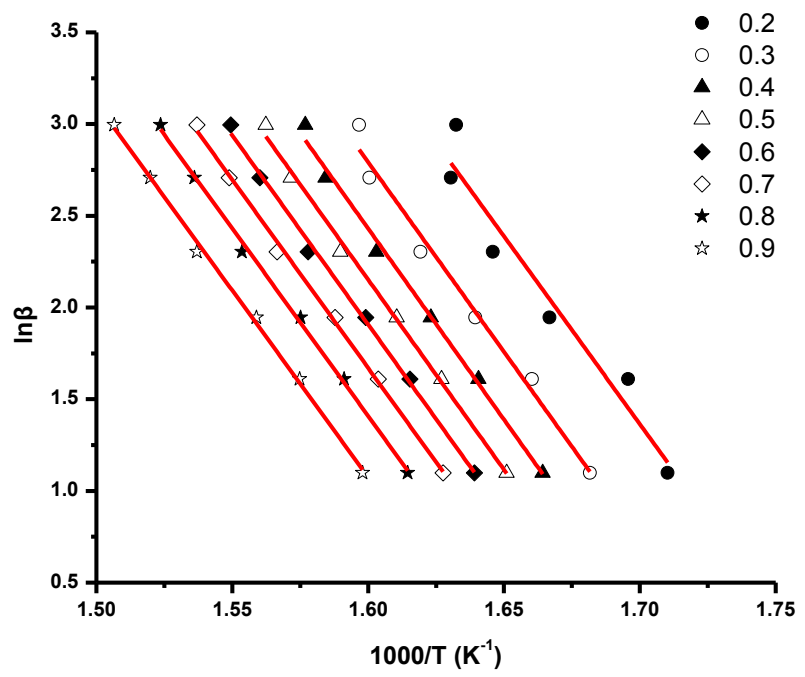

Figure16. OFW plots for P2VP-PDEGMA 60-40

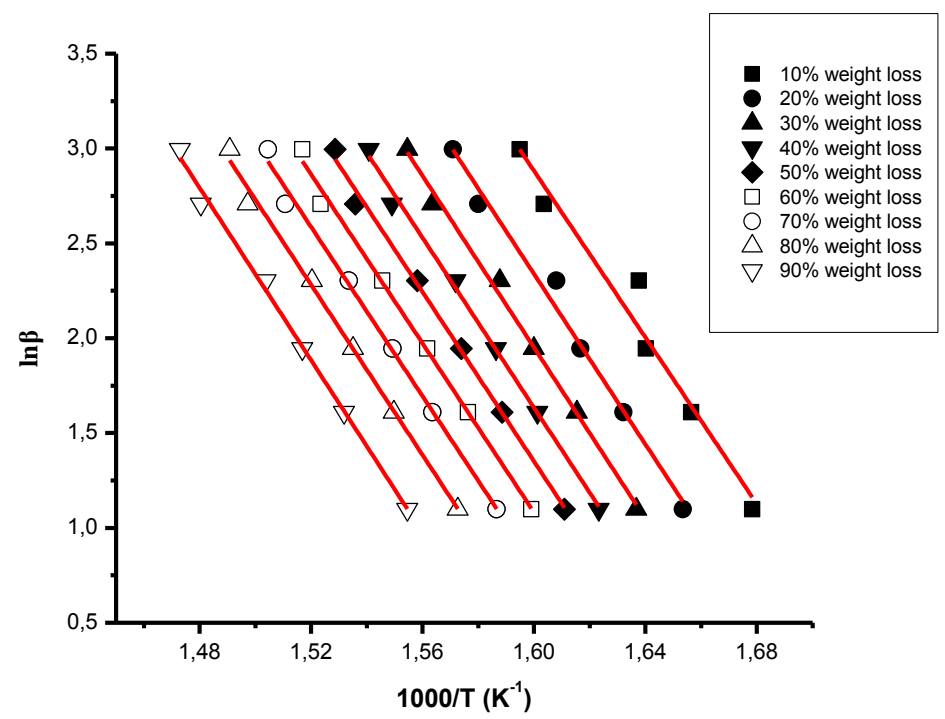

Figure17. OFW plots for P2VP-PBuOEMA 40-60

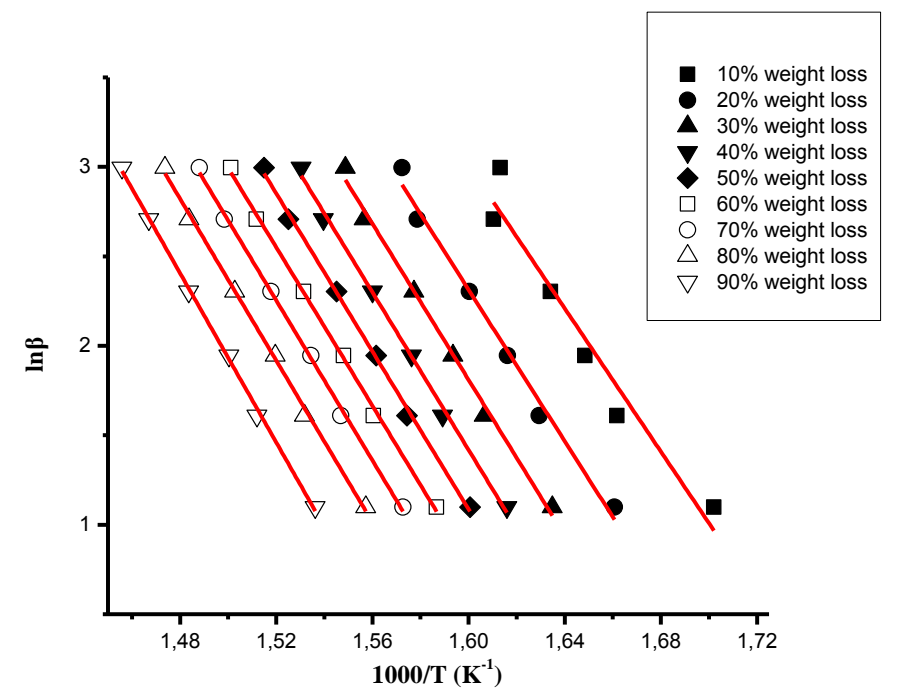

Figure18. OFW plots for P2VP-POEGMA300 60-40 


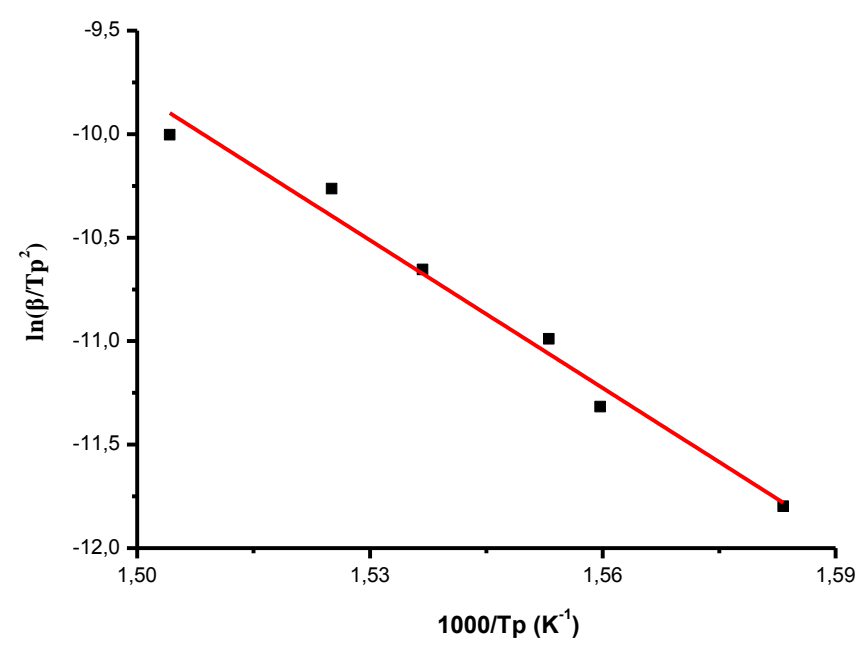

Figure19. Kissinger plot for P2VP-PBuOEMA 50-50

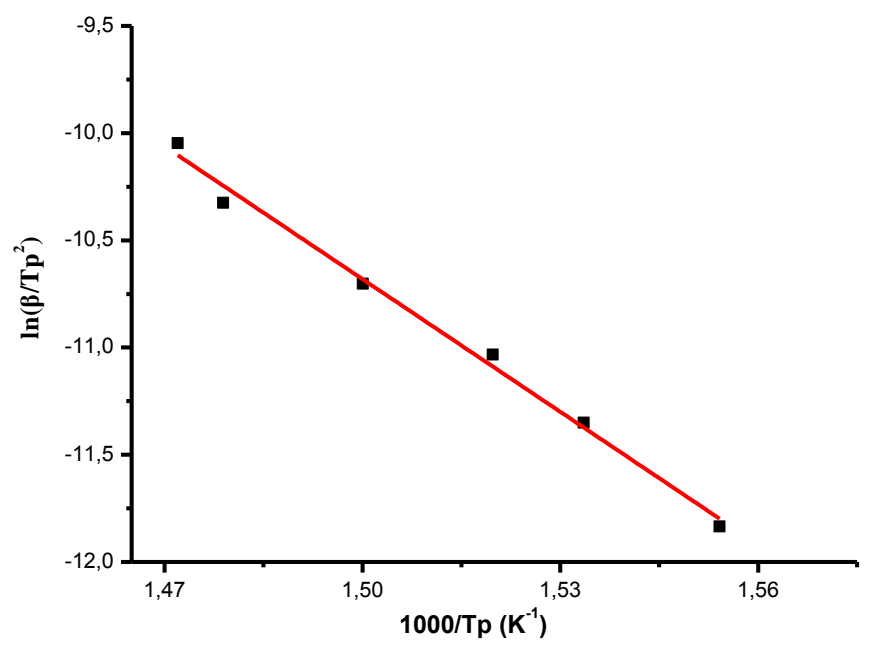

Figure20. Kissinger plot for P2VP-POEGMA300 80-20

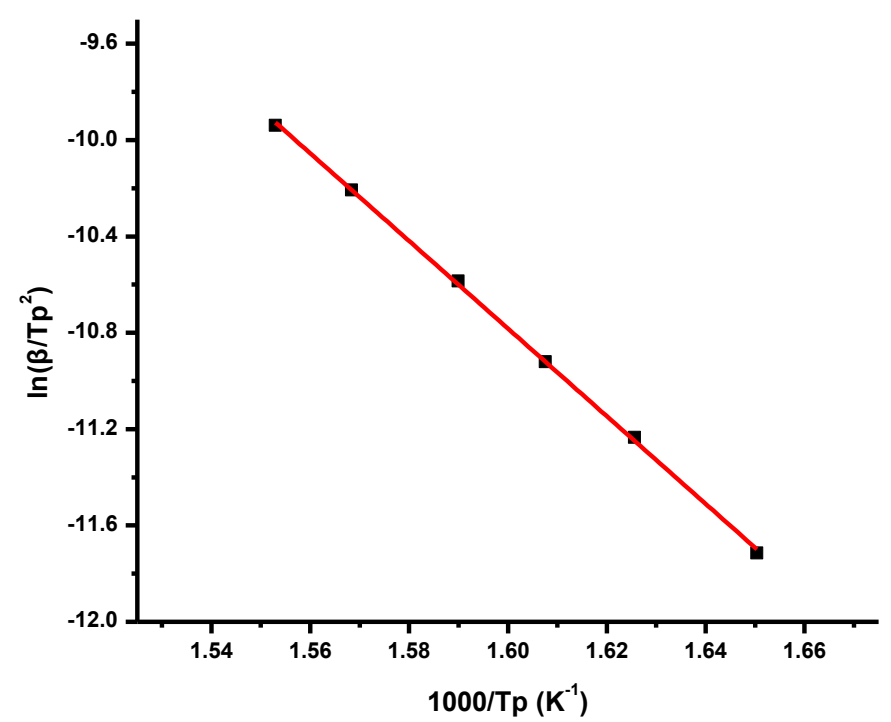

Figure21. Kissinger plot for P2VP-PDEGMA 50-50 


\section{SUPPORTING INFORMATION}

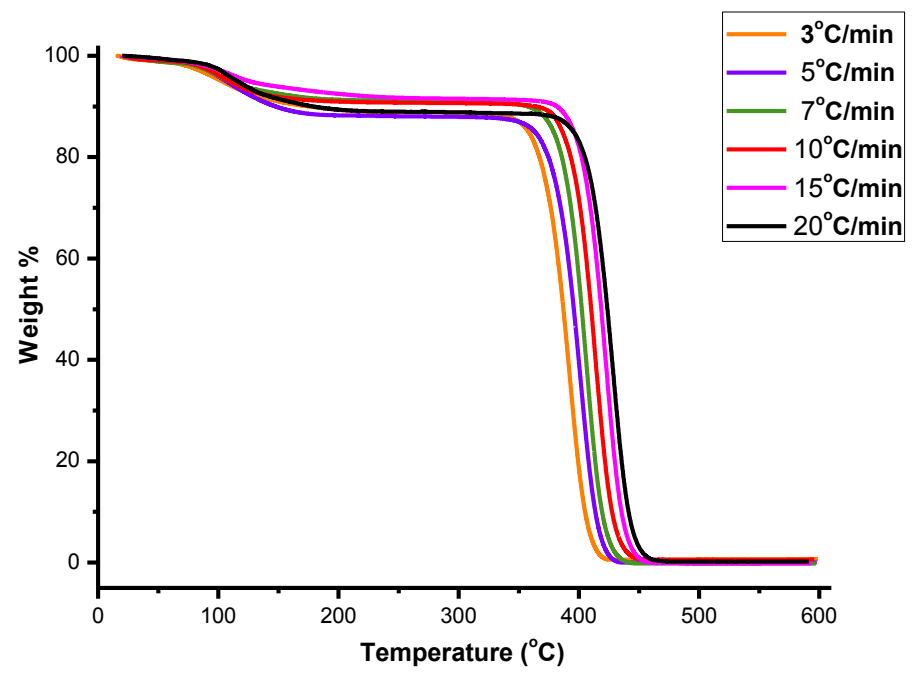

TGA curves for P2VP

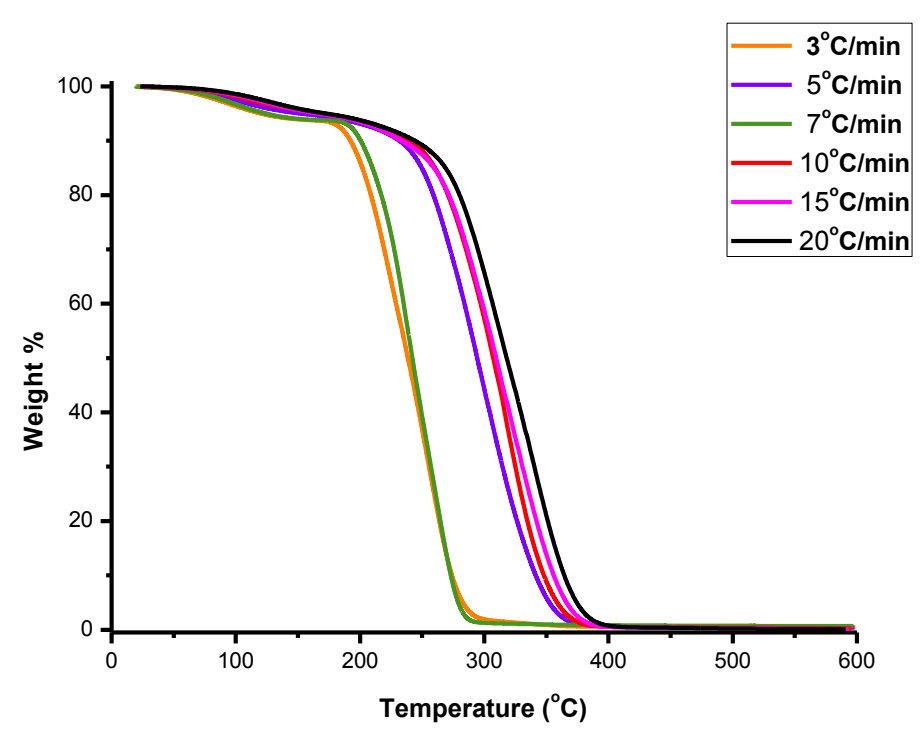

TGA curves for PBuOEMA

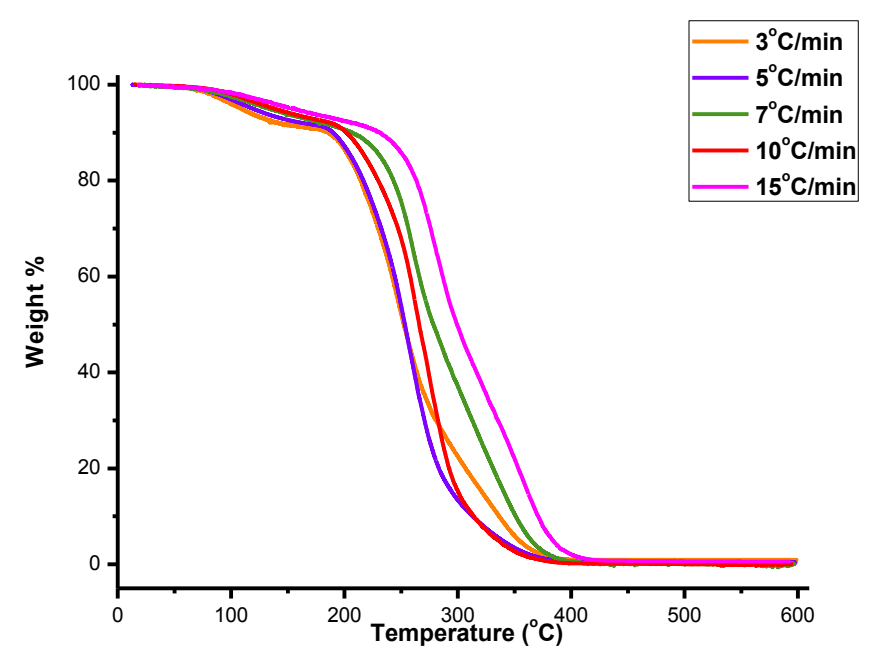

TGA curves for PDEGMA 


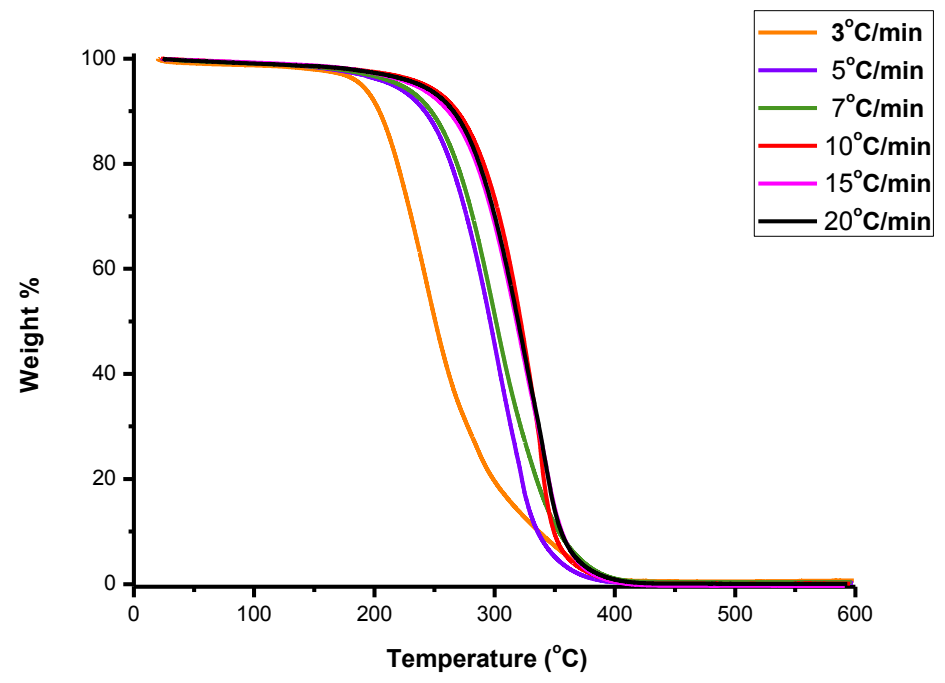

TGA curves for POEGMA 300

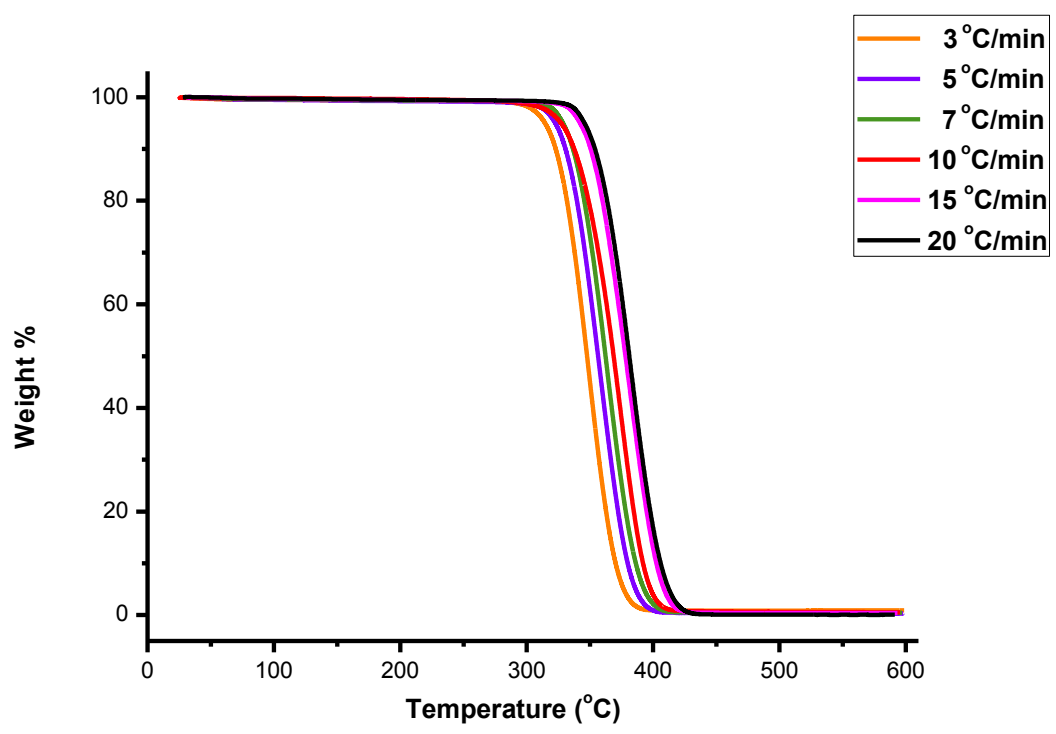

TGA curves for P2VP-PBUOEMA 40-60

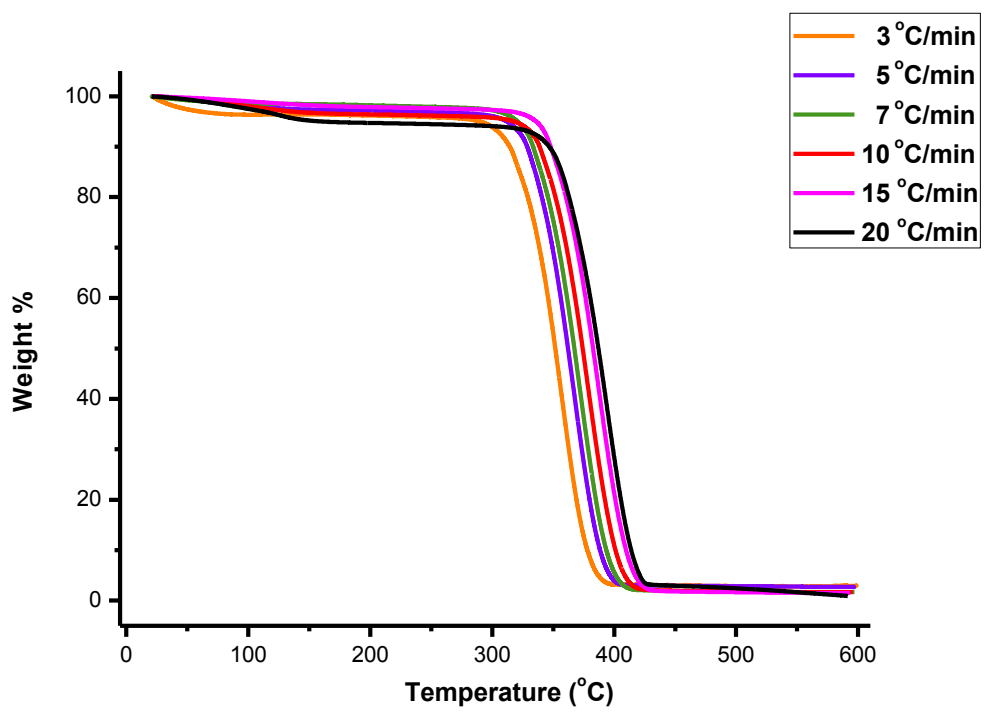

TGA curves for P2VP-POEGMA300 60-40 
It is clear that it is possible to manipulate the thermal decomposition behavior of the statistical copolymers by affecting small changes in the comonomer chemical structure.

\section{CONCLuSION}

The kinetics of the thermal decomposition of statistical copolymers of 2-vinyl pyridine (2VP) with 2butoxyethyl methacrylate (BuOEMA), di(ethylene glycol) methyl ether methacrylate (DEGMA) and oligo(ethylene glycol) methyl ether methacrylate with number average molecular weights $300 \mathrm{~g} / \mathrm{mol}$ $\left(\mathrm{OEGMA}_{300}\right)$ were studied by thermogravimetric analysis (TGA) and differential thermogravimetry (DTG). The results of the corresponding homopolymers revealed that the thermal stability decreases in the order P2VP>POEGMA300>PDEGMA>PBuOEMA. Single decomposition peaks were obtained by DTG for P2VP, whereas a more complex decomposition pattern was obtained for the polymethacrylates, indicating a more complex mechanism of decomposition. The statistical copolymers showed only single decomposition peaks at temperatures located between those of P2VP and the respective polymethacrylate. However, the decomposition temperature at the maximum rate of decomposition is closer to that of $\mathrm{P} 2 \mathrm{VP}$, since the copolymers are richer in $2 \mathrm{VP}$ units. The activation energies of the thermal decomposition were calculated by the Ozawa-Flynn-Wall (OFW) and Kissinger methods. Comparison of the Ea values of the various copolymers leads to the general conclusion that they follow the order: $\mathrm{Ea}_{\text {P2VP-co-PBuOEMA }}>\mathrm{Ea}_{\mathrm{P} 2 \mathrm{VP}-\mathrm{co-OEGMA} 300}>\mathrm{Ea}_{\text {P2VP-co-DEGMA. The same }}$ order was found for the decomposition temperatures at the maximum rate of decomposition of the copolymers, confirming their thermal stability.

\section{REFERENCES}

[1] Zhang, C. and Maric, M., Synthesis of Stimuli-responsive, Water-soluble Poly[2-(dimethylamino) ethyl methacrylate/styrene] Statistical Copolymers by Nitroxide Mediated Polymerization. Polymers 3, 1398-1422, (2011).

[2] Hu, W., Mathot, V. B. F. and Frenkel, D., Phase Transitions of Bulk Statistical Copolymers Studied by Dynamic Monte Carlo Simulations. Macromolecules 36 (6), 2165-2175, (2003).

[3] Fernández-García, M., Torrado, M. F., Martínez, G., Sánchez-Chaves, M. and Madruga, E. L., Free radical copolymerization of 2-hydroxyethyl methacrylate with butyl methacrylate: determination of monomer reactivity ratios and glass transition temperatures. Polymer 41 (22), 8001-8008, (2000).

[4] Kataoka, K., Harada, A. and Nagasaki, Y., Block copolymer micelles for drug delivery: design, characterization and biological significance. Advanced Drug Delivery Reviews 47 (1), 113-131 (2001).

[5] Roman, G., Martin, M. and Joachim, P. S., Block copolymer micelle nanolithography. Nanotechnology 14 (10), 1153, (2003).

[6] Jochum, F. D.; Theato, P., Temperature- and light-responsive smart polymer materials. Chemical Society Reviews 42 (17), 7468-7483, (2013).

[7] (a) Fernández-Monreal, C., Martínez, G., Sánchez-Chaves, M. and López Madruga, E., Solvent effect on the free-radical copolymerization of 2-hydroxyethyl methacrylate with t-butyl acrylate. Journal of Polymer Science Part A: Polymer Chemistry 39 (12), 2043-2048, (2001).

(b) Liu, Y., Mao, R., Huglin, M. B. and Holmes, P. A., Reactivity ratios in copolymerizations involving allyl methacrylate. Polymer 37 (8), 1437-1441, (1996)

(c) Fernández-García, M., de la Fuente, J. L., Fernández-Sanz, M. and Madruga, E. L., An Analysis of the Solvent Effects on the Monomer Reactivity Ratios Using the Copolymer Glass Transition Temperatures. Macromolecular Rapid Communications 22 (6), 451-455, (2001)

(d) Gatica, N., Díaz, F. R., Gargallo, L. and Radić, D., Vinyltrimethylsilane-co-N-vinyl-2pyrrolidone and vinyltrimethoxysilane-co-N-vinyl-2-pyrrolidone copolymers Synthesis and reactivity ratios. Polymer Bulletin 40 (6), 707-713, (1998)

(e) Liaw, D.-J., Huang, C.-C., Sang, H.-C. and Wu, P.-L., Macromolecular microstructure, reactivity ratio and viscometric studies of water-soluble cationic and/or zwitterionic copolymers. Polymer 41 (16), 6123-6131, (2000).

[8] George Odian, Principles of polymerization (third edition), Wiley-Interscience, New York, 1991, $768 \mathrm{pp}$. 
[9] (a) Flory, P. J., Principles of polymer chemistry. Cornell University Press: 1953

(b) P. C. Hiemenz, Polymer chemistry-The basic concepts, Marcel Dekker, New York, 1984, 738 pp. 3.

[10] Driva, P., Bexis, P. and Pitsikalis, M., Radical copolymerization of 2-vinyl pyridine and oligo (ethylene glycol) methyl ether methacrylates: Monomer reactivity ratios and thermal properties. Eur. Polym. J. 47 (4), 762-771, (2011).

[11] Karra, E., Petrakou. I., Driva, P. and Pitsikalis, M., Radical copolymerization of 2-vinyl pyridine with functional methacrylates: Monomer reactivity ratios and thermal properties. Macromolecules: An Ind. J. 9 (2), 68-77, (2013).

[12] (a) T. Ozawa, A new method of analyzing thermogravimetric data, Bull.Chem. Soc. Jpn.1965, 38, 1881-1886;

(b) J. Flynn, L. A. Wall, A quick,direct method for the determination of activation energy fromthermogravimetric data, J. Polym. Sci. Part B: Polym. Lett. 1966, 4,323-328;

(c) T. Ozawa, Kinetic Analysis of Derivative Curves in ThermalAnalysis, J. Therm. Anal. Calorim. 1970, 2, 301-324

[13] (a) H. E. Kissinger, Variation of peak pemperature with heatingrate in Differential Thermal Analysis, J. Res. Natl. Bur. Stand. 1956, 57,217-221;

(b) H. E. Kissinger, Reaction kinetics in thermal analysis, Anal.Chem. 1957, 29, 1702-1712. 